\section{Becoming the World}

\section{Laura Simms}

$\mathrm{T}$ olerance, compassion, wisdom, imagination, responsibility, and creativity are not extra-curricular activities to enhance education, they are the foundation that makes learning possible. Our children deserve and need to live with themselves and others successfully and with meaning. Becoming The World brings together multicultural stories, activities, and information in order to return the wisdom of village elders and the oldest technologies, of imagination and listening, to our children.

Over twenty years ago I spent six weeks with fourth graders in a school in New York City, telling stories and engaging children in creating their own. At the end of our time together I asked the children, "What happened?" Their answers taught me a great deal. All of the children agreed that listening had actually improved their ability to express themselves. A girl said, "I used to hide when my mother was angry at me, now I explain myself." A boy stated, "There are meanings that are real inside the story." Another child piped in, "Because it is like pictures in the mind, it is alive."

I became fascinated by their perceptions. I inquired further, "What would happen if there were no stories in the world?" A hand shot up. It was a boy who had originally assured me that he was not interested in what I was doing. "It would be terrible. Some people need a story to go to sleep. If there were no stories, they would just lie there and wait and wait." "I wouldn't know where I came from." "I wouldn't know who I am." The last answer left us silent:

"If there were no stories in the world, there would be no world, because stories created the world." The profundity of these children's remarks has haunted me ever since. Why does this imaginative, reciprocal even reach children so powerfully, activating intelligence, compassion, resilience, hope and humor, regardless of circumstances?

I sometimes think of a story as a round hole cut into ice. Revealed there is a universe of water as vast as sky, a window thrown open that shows us another world we have never imagined that exists within our own experience. Sometimes the sheer relief of being removed from one's preoccupations, for just a minute, allows the body and mind to relax and refresh itself. This can make it possible to endure the next event, or suddenly be struck by new insight and a more expansive view.

What we so often forget is that regardless of trained ideas, belief systems, upbringing, gender, conditions of life, economic status, color of one's skin, language, perspectives and way of dressing, we are all simply human beings attempting to find release from suffering and a way of being together with conditions that provide safety, necessities, and love. Stories bring home the truth of this lesson. There is a Turkish saying, "A small key opens a big door."

Thirty-five years and countless small keys and big doors later, I am pleased to introduce Becoming the World, a storytelling module created for Mercy Corps. The core of this agency's mission statement "to alleviate suffering" - has sustained me through the various phases of this project, from choosing stories, to designing activities, to readying a team of trainers.

Recent world events have exposed existing levels of fear and stress, confusion and passivity in many of our children. Becoming the
World seeks to stimulate learning from inside the child, at the root of the mind and in the heart, where actual transformation occurs. And in order to accomplish this, we must first start with ourselves.

The Becoming the World workbook and workshops are designed for New York City staff working with youth today. There are nine chapters in all. The first encourages children to know their own story and begin where they are. Seven traditional tales follow that are adapted from diverse cultures. These tales are supplemented by activities that open conversations and strengthen creativity. The last chapter invites children to see themselves as global citizens and stewards of the earth. Each chapter stands on its own, though there is an intrinsic developmental structure in the order presented. Page by page, Becoming the World reinforces a continuous flowering of inner capacities leading to dignity, hope and meaning.

We are all in need of trusting the inner resources we have as human beings. Becoming the World activities help us to reactivate our creativity and wonder about the sacred and mysterious forces that bring us together.

\section{Why Stories Work}

Storytelling is powerful because of the responsive engagement engendered by the relationship between storyteller and listener. Drawn out of self consciousness into the unfolding narrative, held by the voice and intention of the teller, the listener spontaneously joins body and mind as they imagine the entire story within themselves. The result of this involvement is a feeling of attention and calm during the ongoing event, a physical listening that proves both soothing and enlivening.

The listener vicariously feels the dynamics of cause and effect, of being the evil-doer and the hero or heroine, of confronting danger and obstacles, and overcoming chal- 
lenges to become the best of themselves. Anger, rage, happiness, gentleness, fierceness, laziness, heroism, fear, love, destruction, disappointment, and exuberance are confronted without shame or having to escape or be afraid of losing oneself. Presence is continuous. Everyone in the storied event may feel fear, but with the attention of the storyteller (who is not lost in the tale) these emotions flourish in safe containment.

The fact that the narrator is telling a story they know or have told before (the teller knows the end of the tale from the start) and survived, catapults the listener into a journey with great curiosity, abandon and zeal to find out what is going to happen next. The stories get us to the root causes of problems, and are practice for dealing with issues and dilemmas of every sort.

Tales provide a platform for immediate interventions, and at the same time guide youth through subtle stages of emotional development including strengthening the power to focus and reflect, and to truly hear others. A deep abiding sense of trust develops between participants and the teller, with each child feeling personally acknowledged and addressed.

As facilitators of Becoming the World, we encourage participants to strive for responsiveness that is gentle and poignant. Your role is to create a space in which youth can respond openly and begin to speak about their issues and fears. You can either read the stories aloud, or - and this is my strong preference narrate them, speaking them out loud. I have included many 'insider' tips at the end of this article to help you feel comfortable, with both approaches; all aim to bring language alive in a way that encourages children's richest response.

As storyteller I have learned to honor the unexpected and unique way each person participates in a story. During discussions, let every answer be heard, regardless of whether you approve or agree with it. By not seeking to punish, reward, criticize or reshape their intention, you can actually begin to hear what children are telling you, as can the other children. Probing for literal and prepackaged answers to questions is a forced fit. It is an act of aggression that won't fortify the inner capacitates of our children. You can't pry anyone out of the place where they have been safely and habitually feeling and thinking, to respond as you would like them to respond. On the other hand, questions asked with a spirit of 'open ears' can expand children's sense of meaning and confidence in communication.

Our intention is to holistically stimulate feelings, sensations, and imagery for the listener. Deep listening synchronizes the body and mind and exercises children's ' muscles' of sustained awareness, trust in themselves, and deepening ability to engage in the world at large. The child who can imagine with some discipline and emotional receptivity will come to know the effect of behaviors, viscerally.

Without an internal recognition of cause and effect for oneself and for others, there is scant incentive to develop ethical and responsible patterns of behavior.

One way to really know the spirit of another culture is to hear their stories. Literally, to become these stories as you listen is the first step in true multicultural education.

When else do we have the chance to directly access an understanding of differences while receiving the gift of beautiful language and image? The integration of body, mind and heart that occurs in the listening simultaneously relaxes and engages listeners in a way that facilitates their ability to reflect, act without reaction, tolerate differences, and explore new experiences. Having become all sides of a story, being both the witch and the girl she tricks, the snake and the king gives children the potential for transfor- mation. Herein is born the facility to change one's life.

\begin{abstract}
Just as people not knowing that a treasure is hidden in the field, pass over it every day without every finding it, so do these creatures live day after day without ever finding the self within their heart.
\end{abstract}

Chandogya Upanishad 8.3.2

\section{Storytelling as an Inner Guide to Tolerance}

These notes are offered to help you understand the connections between the effect and nature of telling stories and the cultivation of respect for self and others within children. Throughout my book Becoming the World there are references to "being" "resting the mind" "observing" and "containing emotions." These are concepts that are often hard to explain with words. They will be felt as you work with the materials. In the notes to follow, I include some of my thoughts about their underlying importance to the art of storytelling. These ideas are the foundation for Becoming The World, and have grown out of more than thirty years of working with children.

\section{Skills for Promoting Tolerance}

The capacity for Tolerance is inherently within each of us. However, the flowering of this enriching quality is entirely dependent on how each child's mind is trained. Many subtle and enduring experiences can take place during storytelling that are key to activating the discipline of tolerance. The materials, stories and activities of Becoming The World are intended to help children expand their understanding of themselves and others based on experiences that can then be discussed, fortified and nurtured. The following concepts are well worth our attention as they are fundamental to creating gradual and sustainable change in our children.

- Within the individual, being able to endure disturbances, sudden emotion, and/or reactions de- 
pends on the ability to contain feelings.

- Being able to contain feelings depends on the individual's experience of diverse emotions without fear or preconceptions that can only take place when the mind is "settled." Opinions, fears of the unfamiliar and learned reactions blind us. Unless trained otherwise, the innate response is to avoid these uncomfortable feelings rather than being able to apply patience and 'listen, learn and absorb' while maintaining awareness of one's own responses. This capacity is activated because of the way in which children spontaneously imagine all the characters and maintain interest in the event.

- These qualities of listening, learning and absorbing cannot be maintained or utilized through understanding concepts alone. They must be felt, known, experienced and acknowledged to become workable skills.

- Creating calm in the mind of the listener is the first step in embracing this innate potential. Children's focus and relaxation is the clue that this is taking place.

- This containment of feelings also depends on experiencing one's own natural state of being. Neutral and suffused with wakeful curiosity, this natural quality of mind is restored through continuous engagement in the storytelling process. As one listens to a story, one experiences a synchronicity of mind and body that instantly allows for "resting the mind in its natural state." The mind and the body are aware and engaged at the same time. Often felt as enchantment, this invisible byproduct is the most powerful effect of storytelling.

- Regardless of how much this is described on paper, these states of being can only be truly known in the moment when they are experienced. Thus, the activities present in my book provide prac- tice as well as a path towards recognitions that is are experiential, then fortified by discussions and activities.

\section{Promoting Tolerance}

Children are caught in the dilemma of a world dominated by passive manipulative mediums such as television, internet, film, video games and preoccupation with opinions as fact. They are often taught that what is seen outside of themselves, or taught to them by rote, is more real than their own experiences. To return to their own inner resources, they need repealed practice, coupled with the personal tool to embody their own imagination, intelligence and intuition, without fear or reactivity. Talking about the lack of something they have not experienced yet, can only leave them baffled. Discussion and our own dedication to discovery can produce fresh insight and confidence.

The reciprocity of the telling/listening even lays the groundwork for this function. By engaging in imaginative thinking and visualizing exercises, children have the chance to 'own' their own unique experiences, which are always different from those of other children. Their feelings are explored in the complexity, thereby 'contained' so they can recognize that others have a different structure of thinking, cultural, or social, ethnic, or religious - that is as compelling as their own. There are no right or wrong experiences, although there may be appropriate and inappropriate behavior or reactions that cause harm. Without the basis of resting the mind, this is not planted in our children.

Tolerance is much more complicated, and more natural, than blind acceptance. It can be sustained only when one's own feelings are acknowledged and there is sufficient strength to listen to another, recognizing that they feel differently. The ability to contain uncomfortable feelings while actively engag- ing with interest gives birth to tremendous personal healing and empowerment. This is where alternative thinking, spontaneous awareness, and creativity can arise.

Creativity is vital, since without is other realities will be impossible to imagine. Maintaining intolerance demands constant resources of reactivity, guarded interactions and the stress of aggression that isolates and furthers stress.

The more children are given the chance to exercise their imagination with respect and discipline, rather than rules and preconceived ideas, the more they will be able to embrace and accept themselves and thus begin to acknowledge the vast diversity of the world around themselves. Without being able to actualize experience through visualization the child does not gain the capacity to choose the satisfaction of appropriate behavior or trust their ability to rest their mind even while experiencing strong emotions or reactions.

As facilitators you are being asked to make this same journey within yourself as well. This is an enlivening adventure for us all, adults and children. To catch ourselves when we react out of fear or naively side with prejudice, and acknowledge an alternative, is the great hero or heroine's triumph.

Edited and reprinted from Laura Simms with kind permission from Mercy Corps, N.Y., August 2004.

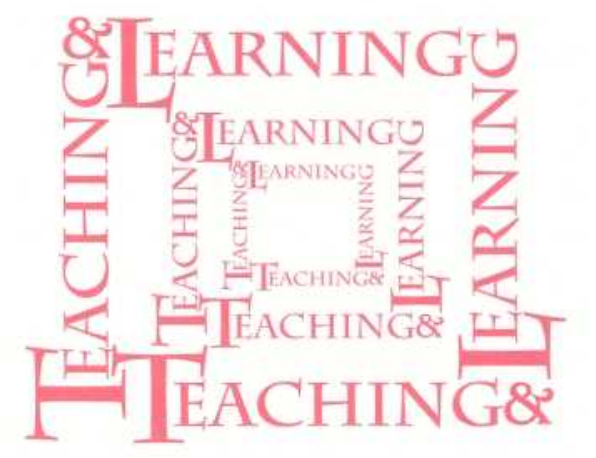

